\title{
ECUADOR: CADA VEZ MENOS DEMOCRACIA, CADA VEZ MÁS AUTORITARISMO... CON ELECCIONES ${ }^{*}$
}

\author{
Ecuador: Less and Less Democracy, More \\ and More Authoritarianism... with Elections
}

\author{
SANTIAGO BASABE-SERRANO \\ German Institute of Global and Area Studies (GIGA) / \\ Facultad Latinoamericana de Ciencias Sociales, FLACSO Ecuador
}

\author{
JULIÁN MARTÍNEZ \\ Facultad Latinoamericana de Ciencias Sociales, FLACSO Ecuador
}

\begin{abstract}
RESUMEN
En el 2013 Rafael Correa afianzó las bases del modelo autoritario-competitivo iniciado en 2007. Más allá de la infraestructura y la inversión pública -que cualquier gobierno con recursos económicos también pudo realizar-, la administración de Correa se caracterizó este año -al igual que en los previos aunque ahora con más intensidad-por la persecución a todo aquel que planteara una opinión contraria a su gestión. En dicho escenario político, el último escollo que queda a Correa para consolidar su permanencia en el poder luego de 2017 es la reforma constitucional que permita la reelección indefinida -o al menos por un período adicional-. Si las condiciones políticas y económicas no varían en el corto plazo, Ecuador tendrá al menos hasta 2021 un gobierno caracterizado por muchas obras públicas y pocas libertades. Más allá de la coyuntura, la gran aceptación popular que genera el modelo autoritario-competitivo de Correa es una de las preguntas clave que debería orientar la investigación científica sobre Ecuador en el futuro inmediato.
\end{abstract}

Palabras clave: Ecuador, autoritarismo competitivo, democracia, Rafael Correa, instituciones políticas.

\begin{abstract}
During 2013 the President Correa strengthened his authoritarian-competitive model initiated at 2007. Regardless of infrastructure and public investment -that any government with economic resources could also have done- the Correa administration was characterized by the persecution of any person with opinions contrary to his performance in office. Given this political scenario, the last obstacle for Correa to consolidate his permanence in office after 2017 was the constitutional reform that permits his reelection without limits -or at least for an additional period. If the political and economic conditions do not vary in the short run, Ecuador will have a government characterized by many public works and few liberties until 2021. Hence, the massive popular acceptance generated by Correa's authoritarian-competitive model should orient future research on Ecuador.
\end{abstract}

Key words: Ecuador, Competitive Authoritarianism, Democracy, Rafael Correa, Political Institutions.

* Los autores agradecen los comentarios y sugerencias de John Polga-Hecimovich y de un árbitro anónimo de Revista de Ciencia Política. 


\section{INTRODUCCIÓN}

El 2013 marcó el afianzamiento del modelo autoritario-competitivo del gobierno de Rafael Correa. Más allá de la obra pública realizada y de la ausencia de suficiente evidencia empírica para valorar los efectos reales de dicha inversión, en Ecuador los espacios para el disenso son cada vez menores. Para ejecutar la política de persecución y amedrentamiento político el gobierno ha recurrido tanto al uso de los recursos estatales como al enjuiciamiento penal de quienes el presidente considera sus "enemigos". La ausencia de controles desde las instituciones de representación política y la situación de dependencia y sumisión del Poder Judicial viabilizan dicha forma de hacer política en el país. En el contexto descrito, la última barrera que deberá derribar el presidente Correa para perpetuarse en el poder es la constitución política diseñada por él mismo y que le impide, de momento, la reelección. No obstante, la abrumadora mayoría legislativa de Alianza País (AP) viabilizará la reforma constitucional en cuanto el Presidente lo indique. De esta forma se habrá allanado el camino para que Correa sea nuevamente candidato y prolongue su gobierno al menos hasta 2021.

Para analizar el 2013 en Ecuador asumimos como referente teórico lo que Levitsky y Way (2002) han denominado "autoritarismo competitivo". Dicho concepto implica el permanente irrespeto a las instituciones políticas formales y la violación secuencial de cuatro criterios mínimos del régimen democrático: a) ejecutivo y legislativo son elegidos mediante elecciones libres, abiertas y justas; $b$ ) virtualmente todos los adultos tienen derecho a votar; c) los derechos políticos y las libertades civiles (libertad de prensa, asociación y de opinión en contra del gobierno) se encuentran protegidas; y, d) las autoridades elegidas tienen libertad para gobernar y no están sujetas al control del ejército o de líderes religiosos (Levitsky y Way, 2002: 53). Como los autores señalan, aunque la violación de cualquiera de los elementos del concepto se podría verificar aun dentro de regímenes democráticos, en los casos de autoritarismos amparados en el ropaje de elecciones dichas violaciones se tornan constantes, al punto de crear una asimetría clara entre el gobierno y la oposición política.

Acorde a la evidencia empírica que presentamos en este artículo consideramos que el caso ecuatoriano se encaja plenamente en el concepto de "autoritarismo competitivo" y que nosotros lo denominamos simplemente modelo autoritario-competitivo, aunque, como se ha dicho, partiendo de los referentes teóricos ya apuntados. Constatamos, por tanto, elecciones regulares aunque con abusos permanentes de los recursos estatales por parte del Presidente y AP; y persecución a opositores políticos, periodistas o cualquier persona que opine públicamente en contra del gobierno. Como bien mencionan Levitsky y Way (2002: 53), regímenes que cometen este tipo de abusos no pueden ser considerados democráticos. Finalmente, evidenciamos también que el proceso que ahora se encuentra cohesionado se inició en el 2007 y que han sido muchos actores -unos aún leales al gobierno y otros ya disidentes- los que han contribuido a la paulatina erosión del régimen democrático. 
Con las premisas teóricas previas, en este artículo analizamos los principales hechos políticos, económicos y sociales suscitados en Ecuador durante 2013. En la primera parte se valora el rendimiento de los principales indicadores económicos, la conflictividad social y la dinámica política nacional e internacional. En la segunda parte, junto a las principales reformas institucionales generadas desde la legislatura, se ofrece un análisis descriptivo de los resultados electorales relacionados con la renovación total de la Asamblea Nacional. Posteriormente se describen las lógicas de relacionamiento entre Ejecutivo, Legislativo y Judicial. El artículo concluye con una valoración general sobre el estado de la democracia en Ecuador haciendo hincapié en el hecho de que, a pesar del deterioro de las instituciones democráticas y las restricciones a las libertades ciudadanas, el electorado sigue aprobando mayoritariamente el modelo autoritariocompetitivo impuesto por el presidente Correa.

\section{TEMAS SALIENTES EN LA REALIDAD NACIONAL Y SU IMPACTO POLÍTICO}

\section{Coyuntura social}

En el 2013 la conflictividad social que enfrentó el gobierno estuvo relacionada principalmente con protestas de sectores afectados por reformas institucionales de diverso orden. La tipificación del aborto o el alcance de la responsabilidad de los médicos en casos de mala práctica fueron algunos de los temas del nuevo código orgánico integral penal (COIP) que motivaron reacciones sociales. La regulación oficial para el uso personal de drogas sujetas a control o la aplicación de la nueva ley orgánica de educación superior también generaron protestas de diferentes sectores de la población. No obstante, la decisión gubernamental de dejar sin efecto, al menos parcialmente, la Iniciativa Yasuní ITT (Itshpingo-Tambococha-Tiputini) fue el punto neurálgico en la conflictividad del año analizado.

Durante octubre de 2013 se hicieron públicas las primeras protestas por la tipificación del aborto en el proyecto de COIP. Grupos organizados, como el Movimiento Nacional de Mujeres Feministas del Ecuador y otros, planteaban la despenalización absoluta del aborto, la no criminalización de la protesta social y la inclusión de delitos sexuales. ${ }^{1}$ Luego de varias semanas de debate público, el texto final del COIP -aprobado en 2014mantuvo como figura delictiva la interrupción del embarazo en caso de violación, con la única salvedad de que la mujer presente discapacidad mental (numeral 2 del Art. 150).

De otro lado, la tipificación de la mala práctica médica en el proyecto de COIP movilizó también a este gremio. ${ }^{2}$ La principal demanda tenía que ver con las presunciones de responsabilidad penal que el código proponía respecto del libre ejercicio profesional de

1 Ver la nota de prensa de Diario Hoy de 8 de octubre de 2013: http://www.hoy.com.ec/noticias-ecuador/lospedidos-de-las-mujeres-a-medias-en-el-codigo-penal-592408.html

2 Al respecto se puede acudir a la edición del día 22 de octubre de 2013 de Diario El Comercio: http://www. elcomercio.com/politica/CodigoPenal-medicos-protesta-malapractica-Ecuador_0_1015698502.html 
los médicos. A pesar de las negociaciones verificadas entre los sectores afectados y el gobierno, a inicios de 2014 se aprobó el COIP bajo el mismo texto inicialmente planteado. Como consecuencia de ello, los médicos tomaron varias medidas de hecho, entre ellas la renuncia a sus cargos en varios hospitales públicos del país. ${ }^{3}$ Luego de que el gobierno se empeñó en negar la protesta de los médicos, finalmente las partes llegaron a un acuerdo consistente en solicitar la interpretación judicial de la parte pertinente del delito de homicidio culposo por mala práctica profesional (inciso tercero del Art. 146 COIP). ${ }^{4}$ En junio, el Consejo Nacional de Control de Sustancias Estupefacientes y Psicotrópicas (CONSEP) reguló la dosis de uso personal de algunas drogas sujetas a control. Entre otros objetivos, dicho acto administrativo buscaba diferenciar la población carcelaria procesada por tráfico de drogas respecto de aquella calificada como consumidora. Esta medida generó reacciones de diverso orden, principalmente de quienes consideraban que la decisión fomentaría el consumo de drogas y, a la par, no contribuiría en mayor medida a la reducción de la población carcelaria. ${ }^{5}$ De otro lado, la aplicación de la ley orgánica de educación superior y otras normas conexas llevaron al cierre de carreras y universidades a nivel nacional y a la jubilación obligatoria de más de 900 profesores que superaban la edad máxima establecida para el retiro. ${ }^{6}$

Sin embargo, el mayor episodio de protesta social se registró a mediados de año tras la decisión presidencial de dar por terminada la Iniciativa Yasuní ITT.7 Este anuncio provocó una intensa y constante movilización de diversos sectores sociales, principalmente organizaciones ecologistas e indigenistas. Tras varias semanas de enfrentamientos y denuncias de represión gubernamental hacia los manifestantes, diferentes organizaciones plantearon la posibilidad de someter a consulta popular el futuro de la Iniciativa Yasuní ITT. Para el efecto se encuentra actualmente en marcha un proceso de recolección de firmas que permita cumplir con los requisitos formales que se requieren previo a solicitar al Consejo Nacional Electoral (CNE) el citado mecanismo de democracia directa. ${ }^{8}$

\section{Coyuntura económica}

En términos generales, el consumo y la inversión pública fueron los componentes que más contribuyeron al desempeño de la economía en 2013 (Cepal, 2013b). Siguiendo la

3 Las renuncias se dieron en diversos hospitales del país. Al respecto, ver la nota de Diario Hoy del día 24 de enero de 2014: http://www.hoy.com.ec/noticias-ecuador/en-ambato-los-medicos-se-suman-a-las-renuncias-599551.html

4 Ver la nota de prensa de Diario El Comercio del día 30 de enero de 2014. http://www.elcomercio.com/salud/ Ecuador-medicos-Codigo_Penal-coip-mala_practica_medica-salud_0_1075692619.html

5 Al respecto ver nota en Diario Hoy del día 20 de junio de 2013: http://www.hoy.com.ec/noticias-ecuador/ el-consep-fijo-la-dosis-personal-de-cuatro-drogas-584045.html

6 Al respecto ver nota de Diario Hoy del 27 de abril de 2013: http://www.hoy.com.ec/noticias-ecuador/launiversidad-publica-579857.html

7 Al respecto ver nota en diario El Telégrafo del 16 de agosto de 2013: http://www.telegrafo.com.ec/economia/ item/se-afectara-menos-del-1-por-mil-del-yasuni.html

8 El artículo 104 de la Constitución de Ecuador y el artículo 195 de la Ley Electoral (Código de la Democracia) establecen que para llevar a cabo una consulta popular se requiere el respaldo en firmas de al menos el 5\% de las personas inscritas en el padrón electoral. Adicionalmente, es necesario el dictamen de la Corte Constitucional sobre la constitucionalidad de la o las preguntas. 
tendencia marcada desde 2011, Ecuador creció menos en el año que se analiza. Si se compara la tasa de crecimiento de 2013 (3,8\%) con la del año inmediato anterior (5\%) o con la de 2011 (7,4\%) dicha afirmación se confirma (Cepal, 2013b: 1). Las causas de este fenómeno estarían, a juicio de la Comisión Económica para América Latina y el Caribe (CEPAL), en las condiciones poco favorables del contexto internacional y en la desaceleración del gasto público del país (Cepal, 2013a: 1). Aunque la inflación continuó descendiendo, de 4,2\% en 2012 a $2 \%$ en octubre de 2013 -considerando el dato acumulado en 12 meses-, el comportamiento de esta variable se daría como consecuencia de la menor dinámica del crecimiento y del menor incremento de los precios con relación a 2012 (Cepal, 2013b: 3).

En cuanto al gasto total del gobierno central, si se comparan los períodos enero-julio de 2012 y 2013 se observa un incremento de 14,2\%. Siguiendo la lógica gubernamental impuesta desde 2007, en el año que se analiza aumentó el gasto en compra de bienes y servicios $(26,3 \%)$, pago de intereses $(44,9 \%)$ y pago de sueldos $(8,45 \%)$. Nominalmente, el gasto central se incrementó en 16,5\% y como consecuencia el gobierno central registró un déficit en contraste con el superávit alcanzado en 2012 (Cepal, 2013b: 1). Adicionalmente, la deuda pública total del sector no financiero se incrementó tanto en lo relacionado con la deuda interna como externa. Respecto de esta última, el monto de la deuda fue el equivalente al 13,9\% del PIB, un punto porcentual más que en el año previo.

En la línea de la estrategia gubernamental de orientar las fuentes de financiamiento hacia China, para septiembre de 2013 la deuda de Ecuador con instituciones de ese país ascendía a 4.500 millones de dólares (Cepal, 2013b). Para obtener una visión comparada de la dependencia ecuatoriana a capitales chinos, la Tabla 1 evidencia los montos de

Tabla 1. Países beneficiarios de créditos del BM, BID y China (entre 2005 y 2011)

\begin{tabular}{lcrrr}
\hline \multicolumn{1}{c}{ Países } & Créditos totales & \multicolumn{1}{c}{ BM } & \multicolumn{1}{c}{ BID } & \multicolumn{1}{c}{ China } \\
\hline Venezuela & 52.528 & $0(0 \%)$ & $6.026(11,47 \%)$ & $46.500(88,52 \%)$ \\
Brasil & 39.628 & $15.338(38,70 \%)$ & $12.559(31,69 \%)$ & $11.731(29,60 \%)$ \\
Argentina & 28.874 & $7.164(24,81 \%)$ & $9.610(33,28 \%)$ & $12.100(41,90 \%)$ \\
México & 27.410 & $14.739(53,77 \%)$ & $11.671(42,57 \%)$ & $1.000(3,64 \%)$ \\
Colombia & 12.118 & $6.241(51,50 \%)$ & $5.877(48,49 \%)$ & $0(0 \%)$ \\
Ecuador & 9.864 & $153(1,55 \%)$ & $2.457(24,90 \%)$ & $7.254(73,54 \%)$ \\
Perú & 6.113 & $3.045(49,81 \%)$ & $2.868(46,91 \%)$ & $200(3,27 \%)$ \\
El Salvador & 2.954 & $1.196(40,48)$ & $1.758(59,51 \%)$ & $0(0 \%)$ \\
Guatemala & 2.887 & $1.176(40,73 \%)$ & $1.711(59,26 \%)$ & $0(0 \%)$ \\
Panamá & 2.811 & $591(21,02 \%)$ & $2.220(78,97 \%)$ & $0(0 \%)$ \\
Costa Rica & 2.741 & $698(25,465 \%)$ & $1.743(63,58 \%)$ & $300(10,94 \%)$ \\
Rep. Dominicana & 2.555 & $854(33,42 \%)$ & $1.701(66,57 \%)$ & $0(0 \%)$ \\
Otros & 13.619 & $2.169(15,92 \%)$ & $6.730(49,41 \%)$ & $4.720(34,65 \%)$ \\
Total & 204.102 & $53.364(26,14 \%)$ & $66.933(32,79 \%)$ & $83.805(41,06 \%)$ \\
\hline
\end{tabular}

Fuente: Gallagher et al., 2013. 
los créditos otorgados por instituciones de ese país como también por parte del Banco Mundial (BM) y el Banco Interamericano de Desarrollo (BID) a países de América Latina. La dependencia de más del 70\% a capitales chinos -solo superada por Venezuela en términos porcentuales- no sería en sí mismo un inconveniente si no existiera evidencia empírica que constata que las tasas de interés y en general los términos contractuales de los créditos con ese país son menos beneficiosos que los que se podría acordar con el BM o el BID (Gallagher et al., 2013).

En cuanto a los desempeños del país en el plano comercial, en el 2013 tanto la balanza de servicios como la de renta volvieron a ser deficitarias, siguiendo así la tendencia observada en años anteriores (Cepal, 2013b). En relación con la balanza comercial sí se detectaron cambios, pues a pesar de que los ingresos por exportaciones de bienes aumentaron en 2,6\% respecto del 2012, las importaciones se incrementaron también en $7,6 \%$. Como consecuencia de lo anotado, dentro de los tres primeros trimestres de 2013 el déficit de la balanza comercial ecuatoriana fue de 821 millones de dólares, mientras que en el mismo período del 2012 existió un superávit de 114 millones de dólares (Cepal, 2013b). ${ }^{9}$

Respecto de la inversión en infraestructura, para finales de 2013 el Ministerio de Transportes y Obras Públicas reportó que de los 9.581,27 km de carreteras manejadas por la red vial estatal apenas el 4,77\% se hallaba en mal estado. ${ }^{10}$ Por otro lado, en el 2013 el número de personas incluidas en el Bono de Desarrollo Humano aumentó en relación con el 2009, pasando de 1,6 a 1,9 millones de beneficiarios, aproximadamente. ${ }^{11}$ En la lucha contra la pobreza se reportó una disminución de $35,3 \%$ a 32,2\%, mientras que la indigencia también arrojó resultados positivos, pues este dato pasó de 13,8\% a 12,9\% (Cepal, 2013c: 17). En el campo de la seguridad social la afiliación al servicio de salud del trabajo doméstico también presentó incrementos notables en el período analizado (Cepal, 2013c: 35).

En el plano laboral, el dato otorgado por el Instituto Ecuatoriano de Estadísticas y Censos (INEC) para el mes de diciembre de 2013 señala que la tasa de desempleo nacional descendió respecto del mismo mes de 2012 en $0,19 \%$ (5,04\% a 4,86\%, respectivamente). No obstante, el subempleo visible a diciembre de 2013 fue de $8,08 \%$, lo que implica un aumento de más de dos puntos porcentuales respecto de diciembre de 2012 (6,07\%).

$9 \quad$ El incremento de las exportaciones de bienes se debe a la mejora en cuanto a la salida de productos primarios (6,5\%), especialmente camarón. Dicho movimiento compensó en alguna medida la disminución observada en cuanto a la exportación de productos industriales, que a septiembre de 2013 presentaba una cifra negativa de $-11,1 \%$ respecto del 2012 (Cepal, 2013b). En cuanto al aumento de las importaciones, el principal rubro se encuentra en los combustibles y lubricantes $(14,7 \%)$, las materias primas $(9,8 \%)$, los bienes de capital $(4,9 \%)$ y los bienes de consumo $(0,9 \%)$.

10 El detalle del estado de la red vial estatal se encuentra en: http://www.obraspublicas.gob.ec/wp-content/ uploads/downloads/2013/10/10-10-2013-Estado-de-la-Red-Vial_MTOP.pdf

11 Sobre los datos para 2009 se puede acudir a: http://www.rlc.fao.org/es/prioridades/seguridad/ingreso4/pdf/ ecuador.pdf La información para 2013 fue tomada de declaraciones de la entonces ministra coordinadora de la política económica, Jeannette Sánchez, a Diario Hoy (18 de enero de 2013). http://www.hoy.com.ec/ noticias-ecuador/bono-de-desarrollo-humano-esta-financiado-571846.html 


\section{Coyuntura subregional e internacional}

Uno de los eventos de mayor relevancia internacional para Ecuador en 2013 fue la solicitud de asilo político del exanalista informático de la Agencia Central de Inteligencia (CIA) y de la Agencia Nacional de Seguridad (NSA) de los Estados Unidos, Edward Snowden. Los primeros días de junio, desde Hong Kong, Snowden hizo público que él fue quien reveló información a los diarios The Washington Post y The Guardian sobre una política secuencial de espionaje generada desde el gobierno de Estados Unidos. Como consecuencia, el 8 de junio el gobierno de Estados Unidos revocó el pasaporte a Snowden y solicitó su extradición. Para evitar ser detenido, Snowden logró llegar a Rusia gracias a un salvoconducto concedido por Fidel Narváez, a la fecha cónsul de Ecuador en Londres. ${ }^{12}$ Ante el revuelo internacional que la noticia generó, pocas horas después el gobierno ecuatoriano desautorizó al cónsul, indicando que la emisión del salvoconducto no fue procesada por los canales oficiales pertinentes.

Posteriormente, y en medio de la tensión generada con Estados Unidos por el caso Snowden, el gobierno nacional hizo pública la renuncia del país a los beneficios provenientes de la ley de preferencias arancelarias andinas (ATPDEA). El argumento oficial para dicha decisión fue que "Ecuador no acepta presiones ni amenazas de nadie y no comercia con los principios ni los somete a intereses mercantiles por importantes que estos sean". ${ }^{13}$ Como un mecanismo de compensación a los sectores perjudicados, la Asamblea Nacional tramitó en pocas semanas la denominada ley orgánica de incentivos para el sector productivo. Adicionalmente, y con la finalidad de diversificar las relaciones económicas de Ecuador sobre todo respecto de un posible acuerdo comercial con la Unión Europea, en el último trimestre de 2013 el presidente Correa visitó Francia, Ruisa y Bielorrusia. ${ }^{14}$

Finalmente, a mediados de septiembre el gobierno ecuatoriano inició una campaña mediática de alcance internacional en contra de la petrolera Chevron, acusada de causar daños ambientales en la Amazonía. Esta iniciativa, denominada "La mano negra de Chevron", tuvo como finalidad ejercer presión en el juicio presentado por la petrolera ante el Tribunal Internacional de La Haya y que guarda relación con el supuesto incumplimiento del gobierno del Ecuador respecto del Tratado Bilateral de Protección de Inversiones (TBI). Adicionalmente, la campaña mediática buscaba persuadir a Chevron para que se someta al fallo de la justicia ecuatoriana en el caso que los pobladores de Sucumbíos iniciaron en 1993 y que la obliga a pagar aproximadamente 19 billones de dólares como indemnización por daños ambientales. ${ }^{15}$

12 Detalles sobre los hechos relatados pueden hallarse en la nota del Diario The Washington Post del 23 de junio de 2013: http://www.washingtonpost.com/world/snowden-departs-hong-kong-for-a-third-countrygovernment-says/2013/06/23/08e9eff2-dbde-11e2-a9f2-42ee3912ae0e_story.html

$13 \mathrm{Al}$ respecto ver la nota de Diario El Comercio de 27 de junio de 2013: http://elcomercio.com/politica/Snowdenasilo-Ecuador-espionaje-NSA_0_945505536.html

14 Ver la nota periodística de Diario El Telégrafo de 13 de noviembre de 2013. http://www.telegrafo.com.ec/ economia/item/ecuador-va-rumbo-a-un-tratado-comercial-con-la-union-europea.html

15 Detalles sobre este caso pueden obtenerse en la nota de Diario El Telégrafo del 22 de noviembre de 2013:http:// www.telegrafo.com.ec/politica/item/la-demanda-internacional-de-chevron-es prematura.html 


\section{Coyuntura política}

La coyuntura política del 2013 estuvo marcada por las elecciones generales y el incremento de la intolerancia política del presidente Correa hacia cualquier voz contraria a su gestión. A pesar de este rasgo autoritario, o quizás como consecuencia de dicho comportamiento, Correa fue reelegido en su cargo sin necesidad de segunda vuelta electoral. Aunque el candidato Guillermo Lasso obtuvo una considerable cantidad de votos válidos $(22,26 \%)$, la hegemonía del candidato-Presidente es inobjetable. Como en procesos electorales previos, nuevamente el gobierno hizo uso de recursos estatales para la promoción electoral. ${ }^{16}$ Adicionalmente, el Consejo Nacional Electoral (CNE) impidió la participación de algunas organizaciones políticas, como Concertación Nacional. ${ }^{17}$

Sin dejar de tener presente el hecho de que la imparcialidad del CNE -ahora presidido por un cercano colaborador del gobierno y antes dirigido por el actual Secretario Particular de la Presidencia ${ }^{18}$ - se ha encontrado siempre en duda, los resultados electorales constantes en la Tabla 2 permiten realizar algunas lecturas sobre el escenario político ecuatoriano en el corto plazo. ${ }^{19}$ Por un lado, la votación alcanzada por Acosta y Wray -ambos disidentes de AP- $(3,22 \%$ y 1,39\%) deja claramente establecido entre los actores políticos que rodean al presidente Correa que sus posibilidades de éxito electoral están dadas en función de su lealtad al Jefe de Estado. Dicho aprendizaje político se reafirmó con el fracaso electoral de otros actores disidentes del gobierno que participaron en el proceso de renovación de la Asamblea Nacional. ${ }^{20}$ Por otro lado, los resultados observados dan cuenta de la alta popularidad que mantiene el presidente Correa desde 2007, independientemente del modelo autoritario-competitivo que guía la gestión del gobierno.

Más allá de la evidencia de los datos ofrecidos, para describir las elecciones presidenciales de 2013 proponemos un análisis espacial de los posicionamientos políticos de los candidatos en función de dos dimensiones. ${ }^{21}$ La primera se denomina "izquierda-derecha" y tiene

16 Varias organizaciones políticas denunciaron ante el CNE la utilización de recursos públicos en la campaña presidencial de Rafael Correa. No obstante, este organismo nunca tomó medidas al respecto. Detalles se los puede conocer en la nota de prensa de Diario El Comercio del día 22 de enero de 2013: http://www.elcomercio. com/politica/CNE-repuestas-quejas-campana-sucia_0_851914862.html

17 A finales de 2012 el CNE requirió para la reinscripción de los partidos y movimientos políticos la presentación de firmas de respaldo. Luego de un proceso que generó muchas dudas sobre su transparencia, algunas organizaciones políticas fueron impedidas de participar. Entre otras, la nota de Diario Hoy del día 13 de octubre de 2012 otorga detalles al respecto: http://www.hoy.com.ec/noticias-ecuador/la-apelacion-es-elrecurso-legal-de-los-movimientos-descalificados-563879.html

18 Ver nota de prensa de Diario El Telégrafo de 11 de marzo de 2014. Allí se reporta la designación de Omar Simon como Secretario Particular de la Presidencia: http://www.telegrafo.com.ec/politica/item/omar-simones-el-nuevo-secretario-de-presidencia.html

19 Para constatar los vínculos políticos de los integrantes del CNE con el gobierno y especialmente los cargos previamente ocupados por su presidente, Domingo Paredes, se puede acudir a la nota de prensa de Diario El Comercio del día 30 de noviembre de 2011: http://elcomercio.com/politica/CNE-afin-Regimenposesiono_0_599940220.html

20 María Paula Romo, Betty Amores y Fernando González fracasaron en la búsqueda de la reelección sin el apoyo de Alianza País. El exministro Gustavo Larrea tampoco pudo alcanzar una curul por la provincia de Pichincha.

21 En esta parte recurrimos a la estrategia teórico-metodológica y a los datos del proyecto "Ecuador Vota", dirigido por Fernando Méndez, Jonathan Weathley (Universidad de Zurich) y Santiago Basabe-Serrano (FLACSO Ecuador). La ubicación de los candidatos presidenciales en las dimensiones mencionadas se dio a base de su 
Tabla 2. Resultados elecciones presidenciales en Ecuador (votos válidos)

\begin{tabular}{llrcc}
\hline \multicolumn{1}{c}{ Candidato } & Partido & Votación & \% votos válidos & \% votos totales \\
\hline Lucio Gutiérrez & PSP & 578.875 & 6,17 & 6,11 \\
Álvaro Noboa & PRIAN & 319.956 & 3,52 & 3,38 \\
Nelson Zabala & PRE & 105.592 & 1,28 & 1,11 \\
Alberto Acosta & PCK-MPD & 280.539 & 3,22 & 2,96 \\
Guillermo Laso & CREO & 1.951 .102 & 22,26 & 20,61 \\
Mauricio Rodas & SUMA & 335.532 & 4,37 & 3,54 \\
Norman Wray & RUPTURA & 112.525 & 1,39 & 1,18 \\
Rafael Correa & AP & 4.918 .482 & 57,79 & 51,96 \\
Blancos & & 179.239 & & 1,89 \\
Nulos & & 684.027 & & 7,22 \\
Total & & 9.465 .869 & 100 & 100 \\
\hline
\end{tabular}

Fuente: Página web del Consejo Nacional Electoral.

PSP: Partido Sociedad Patriótica; PRIAN: Partido Renovador Institucional acción Nacional; PRE: Partido Roldosista Ecuatoriano; PCK-MPD: Pachacutik-Movimiento Popular Democrático; CREO: Creando Oportunidades; SUMA: Movimiento Sociedad Unida Más Acción; RUPTURA: Ruptura de los 25; AP: Alianza País.

que ver con el peso que se otorga al Estado respecto del mercado en la vida económica, social y política. La segunda dimensión se la describe como "conservador-liberal" y se vincula con la comprensión y apertura de los actores frente a cambios en cuanto a valores sociales y culturales -como la legalización del uso de drogas o el aborto-. El Gráfico 1 representa la matriz que surge de las dimensiones de análisis propuestas y el posicionamiento de cada candidato político.

Una primera idea es que las posiciones de derecha-conservadora tienen una sobreoferta de candidatos y opciones partidistas. Ese espacio político, antes ocupado por el Partido Social Cristiano (PSC), la Unión Demócrata Cristiana (UDC, ex-Democracia Popular) y en alguna medida el Partido Roldosista Ecuatoriano (PRE), ahora cuenta con actores emergentes -Lasso y Rodas-22, pero también con figuras políticas que progresivamente han ido perdiendo fuerza electoral -Gutiérrez y Noboa-. Una segunda interpretación

posicionamiento frente a determinados temas mediante declaraciones, manifiestos de campaña o entrevistas. Posteriormente, los datos fueron enviados a cada uno de los candidatos para que los ratifiquen o alteren. Cuando el candidato solicitó que se lo coloque en una posición diferente, el valor final correspondió a lo que el candidato mencionó. Algunos presidenciables no dieron atención al pedido, por lo que se mantuvieron los valores arrojados por el proyecto. Para más detalles ver: www.ecuadorvota.com o contactar a los responsables de dicho proyecto.

22 Cuando se escribía este artículo Mauricio Rodas competía por la alcaldía de Quito con Augusto Barrera, candidato a la reelección por el movimiento de gobierno. A juzgar por las últimas encuestas disponibles, la diferencia porcentual entre ambos candidatos era mínima por lo que a dos semanas de las elecciones se hablaba de un empate técnico. 
Gráfico 1. Ubicación espacial de candidatos presidenciales en Ecuador

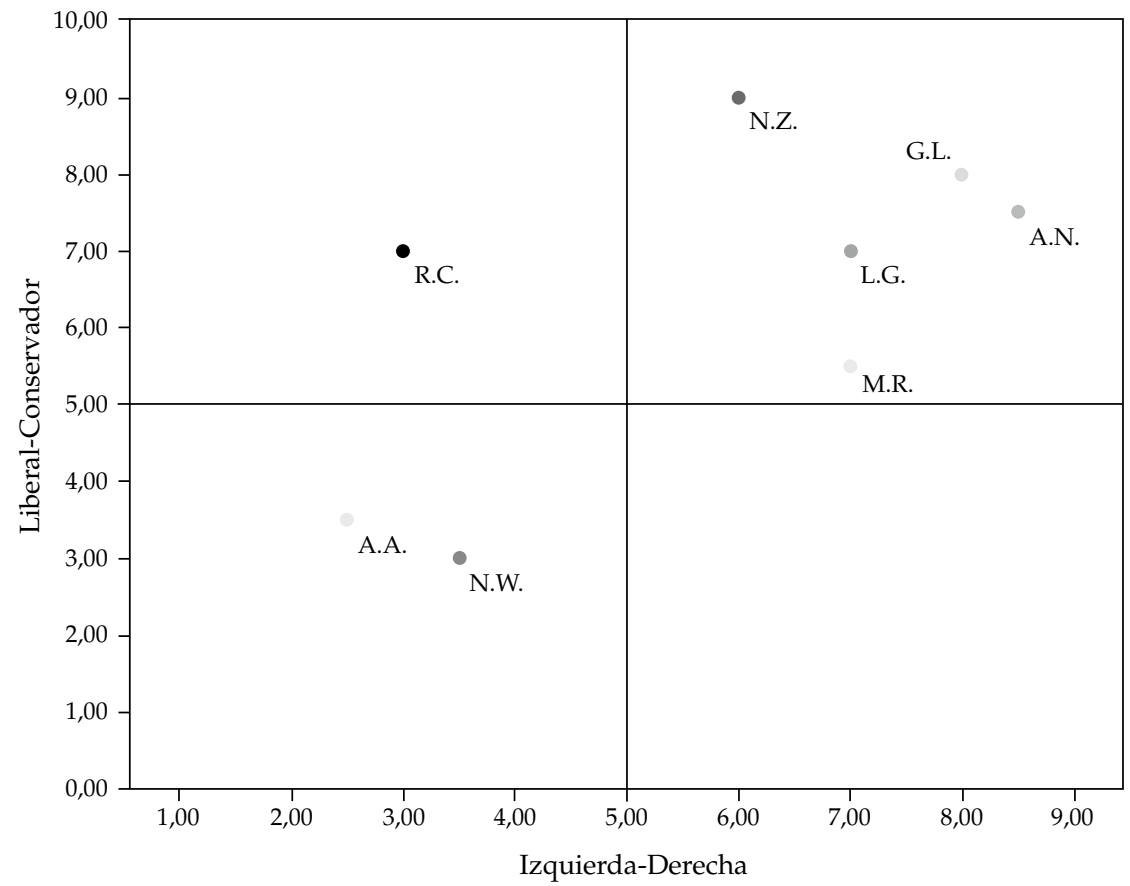

Fuente: Méndez, Weathley y Basabe-Serrano, 2013.

RC: Rafael Correa; AA: Alberto Acosta; NW: Norman Wray; NZ: Nelson Zabala; LG: Lucio Gutiérrez; MR: Mauricio Rodas; GL: Guillermo Laso; AN: Álvaro Noboa.

tiene que ver con la ausencia de opciones políticas de derecha-liberal, tal cual se puede observar en el cuadrante inferior derecho del Gráfico 1. A partir de una revisión histórica de las tendencias ideológicas con influencia en Ecuador, al menos desde el retorno a la democracia, se puede afirmar que dicho espacio siempre estuvo vacío.

Por otro lado, el cuadrante de "izquierda-conservadora" encuentra en el presidente Correa a su único representante. Si se parte del supuesto clásico de la teoría política positiva que afirma que los electores votan a quien más se acerca a su curva de preferencias, el análisis previo daría cuenta de algunos rasgos de la sociedad ecuatoriana. Desde esa perspectiva resulta comprensible también no solo que las opciones ubicadas en el cuadrante superior derecho hayan sido la segunda mejor opción asumida por el votante ecuatoriano en estas elecciones, sino también el predominio de esa tendencia en anteriores procesos electorales. ${ }^{23}$ Siguiendo el mismo supuesto del elector racional, Lucio Gutiérrez se situaron en algún punto del cuadrante de derecha conservadora. Solamente los gobiernos de Osvaldo Hurtado y Rodrigo Borja se ubicaron en las posiciones ideológicas más cercanas al centro político. El análisis espacial previo se refleja también en el posicionamiento político de los partidos a los que pertenecieron los expresidentes al momento en el que sus líderes se encontraban ejerciendo la presidencia. 
las plataformas partidistas desde la izquierda liberal tampoco interpelan lo suficiente al electorado. Los resultados alcanzados por Acosta y Wray dan cuenta de lo dicho. Finalmente, las posiciones ideológicas más centristas se encuentran ausentes de la arena política del Ecuador.

Como se ha mencionado, el otro elemento decisivo de la coyuntura política de Ecuador en 2013 fue el incremento de la persecución política por parte del gobierno hacia quienes presentaron críticas o reparos públicos a la gestión oficial. ${ }^{24} \mathrm{Si}$ bien esta tendencia autoritaria está presente desde 2007 -la inconstitucional destitución de los miembros del Tribunal Constitucional o de cincuenta y siete diputados son solo algunos referentes empíricos de lo mencionado-, en el 2013 se suscitaron otros hechos que dieron cuenta de la radicalización del autoritarismo-competitivo instaurado por el presidente Correa. Para tales fines existen al menos tres herramientas a las que el gobierno acudió. La primera son los denominados "Enlaces Ciudadanos", en los que sábado a sábado el Presidente agrede a quienes opinan públicamente de cualquier forma que no sea de su agrado. ${ }^{25} \mathrm{Un}$ caso decidor en 2013 -entre cientos existentes- es el del artista popular Jaime Guevara, atacado verbalmente por el Presidente por haber demostrado su inconformidad con el gobierno mediante una señal con la mano. ${ }^{26}$

La segunda herramienta de persecución política son los tribunales de justicia. Aunque la captura del Poder Judicial se inició con la reforma constitucional de 2011 -que dio lugar a un Consejo de la Judicatura ad hoc encargado de seleccionar a los jueces de la Corte Nacional-, en 2013 se consolidó dicho objetivo cuando el propio Presidente de la Corte Nacional de Justicia (CNJ) nominó como titular del Consejo de la Judicatura (CJ) a Gustavo Jalkh, una persona abiertamente vinculada con el gobierno. ${ }^{27}$ De esta forma, con el control del órgano de designación y sanción de los jueces, las acciones legales propuestas por el gobierno en contra de sus opositores fueron ágilmente tramitadas y resueltas acorde a sus intereses.

Uno de los casos emblemáticos de persecución por las cortes de justicia es el del asambleísta Cléver Jiménez y su asesor Fernando Villavicencio, condenados a 18 meses de prisión, al pago de ciento cuarenta mil dólares de indemnización y a pedir disculpas públicas

24 Un informe detallado sobre la libertad de expresión en Ecuador durante el 2013 se lo puede obtener en el informe de Fundamedios: http://www.fundamedios.org.ec/sites/default/files/archivos/informefundamedios_4.pdf

25 Periodistas, profesores universitarios, analistas, políticos y cuanta persona tenga un criterio diferente al oficial es ofendido y amenazado por el Presidente. El caso del activista Carlos Zorilla es un buen referente de lo indicado. Por la elaboración de un manual para activistas comunitarios fue tildado de desestabilizador del gobierno ecuatoriano. Al respecto la nota de la agencia pública de noticias "Andes" http://www.andes.info. ec/es/noticias/manual-activistas-comunitarios-amplifica-guerra-desestabilizacion-gobierno-ecuador.html

26 La versión del agredido y la reacción del Presidente durante su "Enlace Ciudadano" pueden ser observadas en la siguiente nota periodística del canal de televisión Ecuavisa: http://www.ecuavisa.com/articulo/ lo-mejor-del-2013/septiembre/39855-jaime-guevara-narra-su-incidente-rafael-correa

27 Antes de asumir la presidencia del CJ, Gustavo Jalkh se desempeñó como ministro y secretario particular del presidente Correa. Acorde a la reforma constitucional de 2011 (Art. 179), quien preside el Consejo de la Judicatura es el delegado del Presidente de la Corte Nacional de Justicia (CN). En la terna propuesta por Carlos Ramírez -titular de la CN-, Jalkh constaba en primer lugar. Posteriormente, el Consejo de Participación Ciudadana y Control Social se encargó de viabilizar la designación. 
al presidente Correa por haber cometido el delito de calumnia judicial. La causa tuvo origen en una denuncia presentada por Jiménez y Villavicencio en la que se decía que el Presidente dispuso la incursión armada al Hospital de la Policía Nacional durante los hechos del 30 de septiembre de $2010 .{ }^{28}$ Otro caso referencial es el de la dirigente del maoísta partido Movimiento Popular Democrático (MPD), Mery Zamora, sentenciada en 2013 a 8 años de prisión por el delito de terrorismo y sabotaje. La acusación decía que esta persona incitó a los estudiantes de un colegio de Guayaquil a salir en apoyo de las manifestaciones y hechos violentos ocurridos en esa ciudad durante el 30 de septiembre de $2010 .^{29}$

A inicios de 2013 un tribunal penal condenó a diez jóvenes a un año de prisión por el delito de terrorismo. ${ }^{30}$ La acusación señalaba que estas personas eran responsables de colocar cuatro bombas panfletarias en las ciudades de Quito, Guayaquil y Cuenca. También en enero de 2013 el dirigente indígena Carlos Pérez recibió una sentencia de ocho días de prisión por el delito de suspensión de servicios públicos a propósito de marchas de protesta contra la ley de aguas y de minería. ${ }^{31}$ En primera instancia el dirigente había sido condenado a un año de prisión por el delito de sabotaje y terrorismo. En julio de 2013, doce estudiantes del Colegio "Central Técnico" fueron sentenciados a veintiún días de prisión por el delito de rebelión. ${ }^{32}$ Los hechos que motivaron este enjuiciamiento fueron protestas estudiantiles que derivaron en actos de afectación a la propiedad privada. Más allá de que en todos estos casos pudieron haberse reproducido hechos reñidos con la ley, la desproporcionalidad de la sanción penal y la gravedad de los delitos imputados dan cuenta de una estrategia gubernamental de persecución y amedrentamiento de la opinión pública. ${ }^{33}$

La tercera herramienta de persecución política son los medios de comunicación públicos y en general cuanta institución estatal se encuentra administrada por personas cercanas al gobierno. El caso de la dirigente Martha Roldós es uno de los que de mejor forma

Sobre la sentencia inicialmente impuesta se puede acudir al Diario El Universo del día 17 de abril de 2013. Posteriormente el caso llegó hasta la CNJ sin que la situación de los enjuiciados haya variado en mayor medida. http://www.eluniverso.com/2013/04/17/1/1355/abogado-correa-confirma-sentencia-asambleistaclever-jimenez.html

29 La sentencia dictada en contra de la dirigente política Mery Zamora fue posteriormente confirmada por una corte de apelaciones. Detalles constan en la siguiente nota de prensa: http://www.larepublica.ec/blog/ politica/2013/11/14/niegan-apelacion-de-mery-zamora-condenada-a-ocho-anos-por-el-30s/

30 El caso fue difundido a través de distintos medios de comunicación y se lo conoce como "Los 10 de Luluncoto", en alusión al barrio de Quito en el que se realizó el allanamiento al domicilio de uno de los jóvenes y en el que la Policía Nacional indicó haber encontrado evidencias suficientes para iniciar un proceso penal por terrorismo. Varias organizaciones de Derechos Humanos realizaron un exhaustivo informe sobre este caso. Al respecto se puede consultar el documento íntegro en: http://www.inredh.org/archivos/pdf/informe_luluncoto.pdf

31 Al respecto se puede acudir a la nota de prensa del Diario El Mercurio del día 22 de enero de 2013. http:// www.elmercurio.com.ec/366048-esta-semana-se-entrega-dirigente-carlos-perez-guartambel/\#.Uv_YsP0nVEQ

$32 \mathrm{Al}$ respecto se puede acudir al Diario El Mercurio del día 15 de febrero de 2014. http://www.elmercurio.com. ec/391083-condenan-a-alumnos-del-central-tecnico/\#.Uv_SSf0nVEQ

33 Con la finalidad de conocer y debatir el estado de persecución política y criminalización de la protesta social, en el mes de septiembre de 2013 en Quito se instaló un tribunal ético. Algunos de los casos han sido expuestos en este artículo. Un detalle de las personas enjuiciadas penalmente por el presunto cometimiento de delitos contra la seguridad del Estado se lo puede obtener en: http://www.argenpress.info/2013/09/ecuador-tribunaletico-por-la-justicia.html 
refleja el uso de este medio de amedrentamiento hacia la oposición política. ${ }^{34}$ De otro lado, mediante decreto ejecutivo de diciembre de 2013 se retiró la personería jurídica a la Fundación ambientalista "Pachamama". Esta organización del tercer sector planteaba demandas reivindicativas en la Amazonía y tenía una posición contraria al gobierno. El argumento oficial fue que la organización no cumplía los objetivos para los que había sido creada. ${ }^{35}$ No obstante, quizás el caso más revelador es el de Xavier Bonilla ("Bonil"), a quien por una caricatura reproducida en el Diario El Universo de la ciudad de Guayaquil, el Superintendente de Comunicación -anterior director de noticias de un canal de televisión incautado- le reconvino a que rectificara una frase citada en dicho trabajo periodístico. Además, Diario El Universo fue sancionado con una multa del $2 \%$ de la facturación de los últimos tres meses. ${ }^{36}$

\section{CAMBIOS INSTITUCIONALES}

Como consta en la Tabla 3, durante 2013 la Asamblea Nacional produjo catorce leyes. Dos de ellas se elaboraron al final del período legislativo previo (2009-2013) y las restantes con la nueva integración de asambleístas elegidos en febrero de 2013. Por sus implicaciones, el cuerpo legal que mayor impacto generó fue la ley orgánica de comunicación. Luego de varias etapas de reformulación y replanteo de textos, y a pesar de la radical oposición de diversos sectores sociales y políticos, en junio la Asamblea Nacional aprobó dicha ley. Las críticas de fondo señalaron que allí se contenían disposiciones orientadas a limitar el derecho de opinión y a generar autocensura. De su lado, el gobierno defendía el argumento que por esa ley se conseguiría democratizar la propiedad de los medios de comunicación y hacer efectivo el derecho a la comunicación de la ciudadanía. Debido al contexto político de persecución existente en Ecuador, esta ley constituye uno de los proyectos emblemáticos del modelo autoritario-competitivo iniciado en 2007.

34 En este caso la agencia pública de noticias "Andes" fue la encargada de perseguir a Martha Roldós, activista política de oposición e hija del expresidente Jaime Roldós. A inicios de 2014 "Andes" denunció que Roldós (a quien no la describió como la hija del expresidente sino como "sobrina del expresidente Abdalá Bucaram Ortiz -destituido de sus funciones en 1997 por actos de corrupción-“) estaría tramitando fondos para una agencia de noticias y una fundación por medio de una organización que podría tener objetivos similares a los de la Agencia Central de Inteligencia (CIA). La nota de prensa consta en: http://www.andes.info.ec/es/noticias/ politica-opositora-ecuador-tramita-ayuda-financiera-ned-eeuu-montar-fundacion-agencia. Posteriormente, en un "Enlace Ciudadano" el Presidente volvió a insinuar vínculos con la CIA por parte de Martha Roldós. El temor que estos mecanismos de persecución generan se encuentra retratado en las declaraciones de Santiago Roldós a los medios de comunicación. Al respecto ver la nota de Diario El Comercio del 15 de enero de 2014. http://www.elcomercio.com/politica/SantiagoRoldos-RafaelCorrea-MilHojas-denuncia_0_1066693392.html

35 En 2009 se esgrimieron los mismos argumentos para cancelar la personería jurídica de la organización "Acción Ecológica", una de las más importantes ONG en temas ambientales. Por la conmoción generada, al poco tiempo el gobierno tuvo que revisar su decisión.

36 Aunque este hecho se verificó en los primeros días de enero de 2014 se lo incluyó como parte del análisis del año anterior. La caricatura y el anuncio de la Presidencia de la República en el sentido de que presentará una queja se los puede ver en el siguiente link: https://www.larepublica.ec/blog/politica/2014/01/04/ presidencia-presentara-queja-caricatura-bonil/ 
Tabla 3. Producción legislativa en Ecuador (2013)

\begin{tabular}{lc}
\hline \multicolumn{1}{c}{ Nombre de la ley } & $\begin{array}{c}\text { Fecha de } \\
\text { publicación }\end{array}$ \\
\hline Reformatoria a la ley de régimen monetario interno y Banco del Estado & $01 / 02 / 13$ \\
Ley para la fijación de límites territoriales internos & $16 / 04 / 13$ \\
Reformatoria a la ley de creación del cantón La Concordia & $21 / 06 / 13$ \\
Orgánica de Comunicación & $25 / 06 / 13$ \\
Orgánica Reformatoria a la ley de minería & $16 / 07 / 13$ \\
Reformatoria del código orgánico de la función judicial & $17 / 07 / 13$ \\
Orgánica de la función de transparencia y control social & $07 / 08 / 13$ \\
Orgánica de incentivos para el sector productivo & $12 / 08 / 13$ \\
Reformatoria a la ley de legalización de tenencia de tierras & $21 / 10 / 13$ \\
Ley para la reparación de las víctimas y la judicialización de graves violaciones a DD.HH. & $16 / 12 / 13$ \\
Creación de la Universidad Regional Amazónica Ikiam & $16 / 12 / 13$ \\
Creación de la Universidad de Investigación de Tecnología Experimental Yachay & $16 / 12 / 13$ \\
Creación de la Universidad de las Artes & $17 / 12 / 13$ \\
Creación de la Universidad Nacional de Educación, UNAE & $19 / 12 / 13$ \\
\hline
\end{tabular}

Fuente: Página web de la Asamblea Nacional del Ecuador. Remitirse a la fuente para obtener el nombre completo de algunas de las leyes enlistadas.

Luego del aparente acuerdo entre la bancada de AP en torno a un articulado específico, la ley orgánica de comunicación fue aprobada con algunos cambios sustanciales. Uno de ellos fue la inclusión en el texto de la figura de un superintendente de comunicación, provisto de amplias capacidades regulatorias y sancionatorias, y cuya designación corresponde al Ejecutivo. De esta forma, no solo las posibles restricciones ya citadas se consagraban normativamente sino que además era una persona cercana al gobierno quien sería la encargada de ejecutar la citada ley. De hecho, una de las primeras consecuencias observables de la ley de comunicación es la ya relatada sanción al caricaturista Xavier Bonilla y al Diario El Universo.

De otro lado, en julio de 2013 se aprobaron importantes reformas a la legislación minera y tributaria relacionada con dicho sector. Acorde con la propuesta del gobierno para su nuevo período, por ese medio se busca reducir los costos de transacción que se generan en el negocio minero y así incentivar la inversión extranjera. A la par, en el mes de agosto entró en vigencia la ley orgánica de incentivos al sector productivo. Dicho cuerpo legal surgió como un medio de compensación a los exportadores ecuatorianos luego de que el gobierno renunciara a los beneficios provenientes de la ley de preferencias arancelarias andinas (ATPDEA). Finalmente, en diciembre se crearon cuatro universidades públicas que serán financiadas con 7.200 millones de dólares de inversión estatal. ${ }^{37}$

37 Al respecto ver la nota de prensa de la agencia pública "Andes": http://www.andes.info.ec/es/noticias/ecuadorpreve-inversion-publica-7200-millones-dolares-2014.html 


\section{RESULTADOS DE ELECCIONES NACIONALES Y SUBNACIONALES}

Junto a las elecciones presidenciales, en febrero de 2013 se renovó íntegramente la legislatura ecuatoriana. Se eligieron quince asambleístas nacionales, ciento dieciséis provinciales y seis en representación de las circunscripciones del exterior (Estados Unidos y Canadá; Europa, Asia y Oceanía; y, América Latina, el Caribe y África). Como se observa en la Tabla 4, la votación alcanzada por AP la ubica como la primera fuerza legislativa del país no solo en este período sino desde el retorno a la democracia. A una considerable distancia se encuentra la bancada del movimiento CREO mientras que con votaciones menores se ubican otras agrupaciones políticas. De esta forma, el control de más de las dos terceras partes de la legislatura permite a AP viabilizar la agenda política del Ejecutivo y, fundamentalmente, superar el último escollo que queda al proyecto autoritario-competitivo del Presidente: la reforma constitucional de cara a permitir la reelección indefinida -o al menos por un período adicional-.

Si se analiza la votación de AP en el plano subnacional se constata también que la representación alcanzada se encuentra distribuida de forma uniforme en todas las provincias del país, incluso en aquellas -como Guayas o Esmeraldas- que hasta hace poco tiempo fueron bastiones electorales del PSC o del PRE. Por tanto, al menos desde

Tabla 4. Resultados electorales para Asamblea Nacional por agrupación política*

\begin{tabular}{lrr}
\hline Agrupación política & $\mathrm{N}^{0}$ de asientos & Porcentaje \\
\hline AP & 100 & 49,80 \\
CREO & 11 & 8,50 \\
PSC/MCMG & 6 & 7,20 \\
PSP & 5 & 5,90 \\
AVANZA & 5 & 5,60 \\
CPI & 5 & 5,50 \\
VARIOS MOV & 3 & 5,40 \\
PRE & 1 & 3,30 \\
SUMA & 1 & 3,20 \\
PRIAN & 0 & 3,10 \\
RUPTURA & 0 & 2 \\
\hline Total & 137 & 100 \\
\hline
\end{tabular}

Fuente: Eichorst y Polga-Hecimovich, 2014.

AP: Alianza País; CREO: Creando Oportunidades; PSC/MCMG: Partido Social Cristiano/Movimiento Cívico Madera de Guerrero; PSP: Partido Sociedad Patriótica; AVANZA: Partido Avanza; CPI: Coordinadora Plurinacional de Izquierdas; VARIOS MOV: Se incluyeron tres movimientos provinciales que alcanzaron representación legislativa; PRE: Partido Roldosista Ecuatoriano; SUMA: Movimiento Sociedad Unida Más Acción; PRIAN: Partido Renovador Institucional Acción Nacional; RUPTURA: Movimiento Ruptura de los 25.

* Para obtener la votación desagregada por provincia de cada partido y movimiento político dirigir correspondencia a los autores de este artículo. 
una perspectiva puramente electoral y sincrónica, AP es una agrupación política de carácter nacional. No obstante, es necesario observar la evolución en los próximos procesos electorales de cara a evidenciar si la premisa anterior se verifica o si, por el contrario, se trata de una votación anclada al personalismo del presidente Correa (PolgaHecimovich, 2013).

Por otro lado, un elemento que marcó diferencia entre este proceso electoral y los anteriores fue la demarcación en distritos electorales de las tres provincias más pobladas del país -Pichincha, Guayas y Manabí-. Más allá de cualquier argumento de orden jurídico, esta fue una decisión política orientada a beneficiar al partido en el gobierno. Así, la combinación de distritos electorales - gerrymandering - con la fórmula aplicada para la asignación de curules -D'Hondt- dio lugar una clara sobrerrepresentación de AP, principalmente en las tres provincias mencionadas. En la circunscripción $\mathrm{N}^{0} 1$ de Pichincha, por ejemplo, AP alcanzó tres de las cuatro curules con el 46,93\% de los votos. En la circunscripción $\mathrm{N}^{\mathrm{o}} 4$ de Guayas, AP obtuvo el 63,85\% de los votos; sin embargo se le asignaron las cinco curules en disputa. Finalmente, a pesar de que en la circunscripción $\mathrm{N}^{\circ} 2$ de Manabí AP -en alianza con el movimiento "Unidad Primero"- alcanzó solamente el 56,49\% de la votación, obtuvo los cinco asientos legislativos.

En cuanto a la representación de género, la nueva Asamblea Nacional cuenta con cincuenta y siete mujeres, que representan el 41,60\% del total de la legislatura. Aunque la presidencia y las dos vicepresidencias están ocupadas por mujeres -Gabriela Rivadeneira, Rosana Alvarado y Marcela Aguiñaga, respectivamente-, no se observa una relación similar en cuanto a quienes dirigen las comisiones legislativas. Acorde a la Tabla 5, de

Tabla 5. Comisiones permanentes de la Asamblea Nacional (2013-2017)

\begin{tabular}{|c|c|c|}
\hline Nombre de la Comisión & Presidente & Partido \\
\hline Justicia y estructura del Estado & Mauro Andino & $\mathrm{AP}$ \\
\hline De los derechos de los trabajadores y la seguridad social & Betty Carrillo & $\mathrm{AP}$ \\
\hline Del régimen económico y tributario y su regulación y control & Oswaldo Larriva & $\mathrm{AP}$ \\
\hline Del desarrollo económico, productivo y la microempresa & Juan Cassinelli & $\mathrm{AP}$ \\
\hline $\begin{array}{l}\text { De soberanía, integración, relaciones internacionales y seguridad } \\
\text { integral }\end{array}$ & Fernando Bustamante & $\mathrm{AP}$ \\
\hline De la biodiversidad y recursos naturales & Carlos Viteri & $\mathrm{AP}$ \\
\hline $\begin{array}{l}\text { De la soberanía alimentaria y desarrollo del sector agropecuario } \\
\text { y pesquero }\end{array}$ & Miguel Carvajal & $\mathrm{AP}$ \\
\hline $\begin{array}{l}\text { De gobiernos autónomos, descentralización, competencias y } \\
\text { organización del territorio }\end{array}$ & Richard Calderón & $\mathrm{AP}$ \\
\hline De educación, cultural y ciencia y tecnología & Ximena Ponce & $\mathrm{AP}$ \\
\hline Del derecho a la salud & Carlos Velasco & $\mathrm{AP}$ \\
\hline De participación ciudadana y control social & Raúl Patiño & $\mathrm{AP}$ \\
\hline De los derechos colectivos comunitarios y la interculturalidad & Zobeida Gudiño & $\mathrm{AP}$ \\
\hline De fiscalización y control político & José Rivera & $\mathrm{AP}$ \\
\hline
\end{tabular}

Fuente: Página web de la Asamblea Nacional. 
las trece comisiones permanentes solamente tres se encuentran presididas por mujeres. En términos de desempeños legislativos, de treinta y tres proyectos de ley presentados ante la Asamblea Nacional durante el actual período legislativo solamente siete fueron patrocinados por asambleístas mujeres $(21,21 \%)$.

\section{PODER EJECUTIVO}

Como ha sucedido a lo largo del gobierno del presidente Correa, en el 2013 el gabinete ministerial presentó esencialmente rotaciones. Junto a los dieciséis cambios -no necesariamente salidas- de ministros se creó el Ministerio de Comercio Exterior -antes una subsecretaría del Ministerio de Relaciones Exteriores- y a la par desaparecieron dos ministerios coordinadores -Patrimonio Cultural y de la Política-. Doce de los cambios ministeriales ocurrieron entre abril y junio, a propósito del inicio del nuevo período presidencial de Correa, y dos renuncias se dieron al finalizar el año. La Tabla 6 describe los cambios en el gabinete ministerial durante 2013.

El cuanto al estilo de gobernar del presidente Correa, las características de su gestión lo ubican como parte de los populismos de izquierda latinoamericanos (Roberts y Levitsky, 2011). En dicho concepto se encuentran aquellos gobiernos cuya legitimidad no se basa en el respeto a las instituciones y en los que la movilización política ocurre de arriba hacia abajo. Por tanto, la legitimidad a la que apelan estos presidentes se encuentra en la autoproclamación del líder como representante del pueblo o de la patria y en la identificación de un enemigo común: la oligarquía, la partidocracia o el pasado (De la Torre, 2013). Así, en el estilo presidencial de Correa se combina una carga de componentes emotivos y tecnocráticos. El "tecnopopulismo", por tanto, supone la incorporación de expertos en altos cargos públicos y a la vez la radicalización de la confrontación, el personalismo y de la idea del líder sacrificado, iluminado y redentor (De la Torre, 2013).

Por un lado, "la tecnocracia remplaza la discusión democrática por la administración de los expertos, y transforma el debate entre propuestas en la imposición de modelos legitimados con la idea de que son científicos, y por lo tanto verdaderos" (De La Torre, 2013: 30). Por otro lado, desde lo discursivo el estilo presidencial erige en el mismo acto al enemigo y elimina al interlocutor. La propaganda masiva, que incluye constantes campañas de desprestigio a personas o instituciones que difieren con el gobierno, así como los "Enlaces Ciudadanos" de los días sábados, cierran los espacios de comunicación argumentativa, inhabilitando la posibilidad del debate crítico (De la Torre, 2013).

\section{PODER LEGISLATIVO}

A causa de la composición de la Asamblea Nacional, la obtención de mayorías dejó de ser un problema de negociaciones subterráneas y acuerdos clientelares, como ocurría antes de la llegada del presidente Correa, y aunque en menor medida en el período legislativo 2009-2013 (Mejía Acosta, 2009; Freidenberg, 2012). Adicionalmente, durante el 2013 se 





observó una férrea disciplina de los legisladores respecto de las decisiones asumidas por AP o, en la mayoría de los casos, por el presidente Correa. Dicho comportamiento puede ser interpretado en términos analíticos como un juego principal-agente en el que aun cuando los asambleístas -agentes- desearían tomar una decisión diferente a la del Presidente -principal-, los costos que esto implica son mayores a los beneficios que podrían obtener (Miller, 2005).

Si se parte del supuesto clásico de los estudios legislativos fundados en la teoría de la elección racional, a los asambleístas les interesa la reelección (Fenno, 1973; Mayhew, 1974). Adicionalmente, los asambleístas conocen que cumplir con dicho objetivo depende en buena medida de mantenerse alineados con el Presidente, pues es él quien tiene la popularidad ciudadana. Luego, mantener las preferencias de los legisladores dentro de la curva de preferencias del Ejecutivo produce un equilibrio político medianamente estable. Los asambleístas aumentan sus probabilidades de reelección y el Presidente disminuye los problemas de riesgo moral que le podrían traer legisladores que alteren la lógica del juego principal-agente. Como corolario, a los asambleístas les interesa que el Presidente se mantenga en funciones indefinidamente -para así ellos prolongar su permanencia en la legislatura- y al Presidente le interesa que ningún asambleísta goce de representación electoral por sí mismo -pues esto dificultaría la dinámica impuesta en la legislatura- ${ }^{38}$

La relación ejecutivo-legislativo anotada toma mayor fuerza aun cuando los asambleístas están informados de casos en los que apartarse de la lógica impuesta ha generado costos evidenciables empíricamente. La salida de AP de María Paula Romo, Betty Amores y Fernando González y su posterior fracaso electoral al intentar la reelección legislativa por otras agrupaciones políticas es una muestra clara de la vigencia del juego principalagente. La suspensión por 30 días en el ejercicio de la legislatura a tres asambleístas de AP -Soledad Buendía, Paola Pabón y Gina Godoy- por haber presentado una posición ideológica diferente a la del presidente Correa en el tratamiento de la despenalización del aborto, es otro referente empírico que informa a los legisladores sobre los costos de asumir el disenso. ${ }^{39}$

\section{RELACIÓN ENTRE LOS PODERES DEL ESTADO Y DISTINTOS NIVELES DE GOBIERNO}

Como se mencionó, en 2013 el gobierno nacional consolidó la captura del Poder Judicial con la designación como presidente del CJ de uno de los hombres más cercanos al

38 Fernando Cordero, expresidente de la Asamblea Nacional, de la Asamblea Constituyente y reelegido por AP para un nuevo período legislativo, dejó su curul antes de posesionarse para asumir la dirección del Instituto Ecuatoriano de Seguridad Social (IESS). Entre los actores políticos de AP quizás Cordero era el que tenía mayor proyección política. Aunque el espacio que ahora ocupa en el IESS le genera visibilidad pública, la influencia política que podía proyectar desde la legislatura abarcaba a un mayor número de sectores.

39 Al respecto ver la nota del Diario El Telégrafo de 29 de octubre de 2013 http://www.telegrafo.com.ec/politica/ item/asambleistas-serian-suspendidas.html 
presidente Correa. Debido a las amplias facultades de administración y sanción que tiene el CJ sobre los jueces, incluso sobre aquellos pertenecientes a la CNJ, la independencia del Poder Judicial se encuentra en duda. Lo dicho no implica afirmar que en el período previo a Correa los jueces gozaban de autonomía respecto de los partidos políticos (Conaghan, 2012). Lo que planteamos es que, desde el retorno a la democracia, la mayor dependencia de los jueces supremos a una agrupación política se ha verificado durante el gobierno de Correa (Basabe-Serrano y Llanos, 2014). La Tabla $N^{o} 7$ presenta el resultado de encuestas de opinión a expertos judiciales sobre la cercanía/vinculación de las diferentes conformaciones del más alto tribunal de justicia de ese país respecto de las agrupaciones políticas.

Uno de los casos más evidentes de injerencia política sobre las decisiones judiciales tuvo lugar durante el último trimestre de 2013. En septiembre, los jueces de la CNJ José Suing y Gustavo Durango -dos de los pocos jueces independientes que quedaban en la $\mathrm{CNJ}$ - fueron suspendidos y posteriormente destituidos de sus cargos por haber resuelto un caso en contra de los intereses del gobierno, representados en el Servicio de Rentas Internas (SRI). ${ }^{40}$ Aunque hasta hace pocos meses los mismos jueces habían dictado fallos

Tabla 7. Influencia partidista en la Corte Suprema/Nacional de Ecuador (1979-2013)

\begin{tabular}{ll}
\hline Período & \multicolumn{1}{c}{ Influencia partidista en la Corte Suprema/Nacional } \\
\hline $1979-1984$ & PCE: 31,25\%; CFP: 8,75\%; IND: 12,5\%; PSE: 12,5\%; PSC: 12,5\%; PLRE: 12,5\% \\
1984-1988 & CFP: 18,75\%; DP: 18,75\%; ID: 18,75\%; PSE: 12,5\%; PSC: 12,5\%; FADI: 6,25\%; PCE: \\
& 6,25\%; PRE: 6,25\% \\
$1988-1992$ & DP: 25\%; ID: 25\%; PSE: 18,75\%; PSC: 18,75\%; FADI: 6,25\%; IND: 6,25\% \\
$1993-1997$ & PSC: 45,16\%; PRE: 22,28\%; ID: 9,67\%; DP: 6,45\%; PSE: 6,45\%; PUR: 6,45\%; MPD: 3,22\% \\
$1998-2004$ & PSC: 61,29\%; DP: 25,8\%; MPD: 6,45\%; ID: 3,22\%; CFP: 3,22\% \\
& PRE: 20\%; PRIAN: 16,66\%; PSC: 13,33\%; MPD: 13,33\%; PSP: 10\%; DP: 6,66\%; PSE: \\
2005 & 6,66\%; CFP: 6,66\% IND: 6,66\% \\
$2006-2008 *$ & PSC: 35,48\%; IND: 35,48\%; DP: 9,67\%; PCK: 9,67\%; ID: 6,45\%; PRE: 3,22\% \\
$2012-2021$ & AP: 77,27\%; IND: 18,18\%; PCK: 4,54\% \\
\hline
\end{tabular}

* Entre 2009 y 2011 estuvo en funciones una Corte Nacional de transición.

Fuente Basabe-Serrano y Llanos, 2014.

PCE: Partido Conservador Ecuatoriano; CFP: Concentración de Fuerzas Populares; PSE: Partido Socialista Ecuatoriano; PSC: Partido Social Cristiano; PLRE: Partido Liberal Radical Ecuatoriano; DP: Democracia Popular; ID: Izquierda Democrática; FADI: Frente Amplio de Izquierda; PRE: Partido Roldosista Ecuatoriano; PUR: Partido Unidad Republicana; MPD: Movimiento Popular Democrático; PRIAN: Partido Renovador Institucional Acción Nacional; PSP: Partido Sociedad Patriótica; PCK: Pachacutik; AP: Alianza País; IND: Independientes.

40 Se trata del juicio tributario que enfrentaba al SRI con la empresa "Oleoducto de Crudos Pesados Ecuador S.A. (OCP)". Ver la nota de prensa del Diario El Mercurio: http://www.elmercurio.com.ec/398285-al-sri-nole-gusta-fallo-judicial-a-favor-del-ocp/\#.UxOqyPl5NTI 
emblemáticos a favor del SRI, tan pronto como la queja fue presentada ante el CJ, este organismo suspendió por noventa días a ambos jueces e inició un sumario administrativo que culminó con su destitución el día 20 de diciembre de $2013 .{ }^{41} \mathrm{El}$ argumento del CJ para destituir a los jueces fue que eran "responsables de las infracciones de falta de motivación y error inexcusable". ${ }^{42}$ Pocos días despuués la Corte Constitucional aceptó un recurso extraordinario de protección presentado por el SRI y dispuso que dentro del caso mencionado se dicte una nueva sentencia. ${ }^{43}$

Respecto de la Asamblea Nacional, en el acápite anterior planteamos ya el análisis del tipo de relación que mantiene con el Ejecutivo y las razones que explicarían dicho comportamiento. Por otro lado, en párrafos previos describimos el estado de las cortes de justicia y la ausencia de autonomía respecto del Ejecutivo. Lo dicho, sumado a la alta popularidad que mantiene el Presidente, da cuenta de un escenario en el que la legitimidad ciudadana en urnas es utilizada por Correa como justificativo para la consolidación de un escenario político en el que la división de poderes es, en los hechos, prácticamente inexistente. Lo dicho, sumado a las distintas formas de represión a cualquier opinión contraria al gobierno, dan cuenta de la consolidación de un proceso autoritario-competitivo iniciado en 2007 y al que resta para su consolidación tan solo la reforma constitucional que permita la reelección indefinida -o al menos por un período adicional- de Rafael Correa.

\section{EVALUACIÓN GENERAL SOBRE EL FUNCIONAMIENTO Y CALIDAD DE LA DEMOCRACIA}

Este artículo ha evidenciado el acelerado deterioro tanto de las instituciones políticas como del respeto a las libertades en Ecuador durante 2013. Aunque este proceso tiene sus inicios en el 2007, a lo largo del año analizado se evidenciaron de forma más clara los rasgos del modelo autoritario-competitivo del gobierno de Rafael Correa. Los medios de comunicación públicos -y los incautados-, los recursos estatales y un Poder Judicial dependiente y sumiso han sido las principales herramientas que el gobierno ha utilizado para perseguir, criminalizar y censurar a cuanta persona opine de forma diferente. Bajo dicho escenario, el último escollo para consolidar el modelo autoritario-competitivo de Correa es la Constitución Política, que a la fecha impide la reelección. No obstante, con la mayoría de AP en la Asamblea Nacional y aun mediante consulta popular, el presidente Correa conseguirá su objetivo de mantenerse en el poder más allá de 2017.

Lo que torna interesante al caso ecuatoriano es que la población sigue apoyando mayoritariamente el modelo autoritario-competitivo en marcha. Según una encuesta de

41 Uno de los casos más importantes que los mismos jueces habían resuelto a favor del SRI es el que mantenía como parte procesal a Bananera Noboa, empresa de propiedad del ex candidato presidencial Álvaro Noboa.

42 La resolución del CJ que destituye a los jueces se encuentra en el expediente disciplinario No D-0879-UCD-2013-PM

$43 \mathrm{Al}$ respecto se puede acudir a la nota de prensa "Corte Constitucional exige emitir otro fallo en litigio entre SRI y OCP". Diario El Telégrafo del 1 de enero de 2014. http://www.telegrafo.com.ec/economia/item/corteconstitucional-exige-emitir-otro-fallo-en-litigio-entre-sri-y-ocp.html 
la firma CEDATOS, a diciembre de 2013 el 65\% de las personas consultadas aprobaba la gestión de Rafael Correa. Dicha medición es superada solamente por la obtenida por el propio Correa en 2007, cuando iniciaba su primer período (68\% de aceptación). ${ }^{44} \mathrm{La}$ relación inversamente proporcional entre fortalecimiento de las instituciones democráticas y apoyo ciudadano al Presidente no deja de ser llamativa, pues precisamente en ese respaldo popular es que se justifica la política de persecución e intolerancia política del gobierno. El Gráfico 2 presenta los niveles de aceptación de Rafael Correa desde su llegada al poder en 2007.

Desde otra perspectiva, se podría argumentar también que la alta aceptación del Presidente tiene relación con la inversión pública generada a lo largo de los últimos años. Independientemente de la sostenibilidad de los proyectos gubernamentales y de la abundancia de recursos existentes como consecuencia de los altos precios del barril del petróleo -los más altos de todo el período democrático-, la agenda del gobierno ha puesto más énfasis en sectores sociales que previamente habían sido relegados. Lo dicho revela que en la escala de preferencias del votante ecuatoriano la provisión de recursos materiales y el estilo de gobierno de Correa se encuentran por delante de las libertades y el Estado de Derecho. Por ello, ceteris paribus las características del escenario político y económico actual, el futuro inmediato del Ecuador estará marcado por la radicalización del modelo autoritario-competitivo de Rafael Correa y el deterioro cada vez más grave del régimen democrático.

Gráfico 2. Aceptación presidencial en Ecuador (2007-2013)
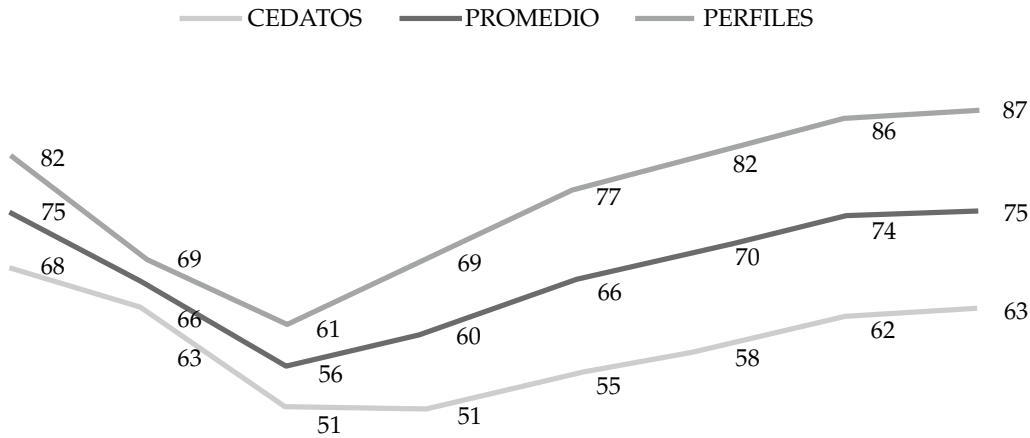

87

75

$2007 \quad 2008$

2009

2010

2011

2012

2013

2014

Fuentes: Cedatos y Perfiles de Opinión.

44 El informe de la firma CEDATOS se encuentra a disposición en el siguiente vínculo: http://www.cedatos.com. ec/detalles_noticia.php?Id=128 


\section{REFERENCIAS}

Asamblea Nacional del Ecuador. www.asambleanacional.gob.ec

Basabe-Serrano, Santiago y Luis Llanos. 2014. “La Corte Suprema del Ecuador en el período democrático (1979-2013): entre la inestabilidad institucional y la influencia partidista". Documento de trabajo. Quito: German Institute of Global and Area Studies y Facultad Latinoamericana de Ciencias Sociales, FLACSO Ecuador-Departamento de Estudios Políticos.

CEDATOS. 2014. "Opinión Ecuador Dic. 2013: Coyuntura Política”. Disponible en: http:/ / www.cedatos. com.ec/detalles_noticia.php?Id=128

Comisión Económica para América Latina y el Caribe (Cepal). 2013a. "Estudio económico de América Latina y el Caribe: Ecuador". Disponible en: http://www.eclac.cl/publicaciones/xml/4/50484/ EEE-Ecuador.pdf

Comisión Económica para América Latina y el Caribe (Cepal). 2013b. "Balance preliminar de las economías de América Latina y el Caribe: Ecuador". Disponible en: http://www.cepal.org/publicaciones/ xml/2/51822/BPE-Ecuador.pdf

Comisión Económica para América Latina y el Caribe (Cepal). 2013c. "Panorama Social de América Latina". Disponible en: http://www.cepal.org/publicaciones/xml/9/51769/PanoramaSocial2013.pdf

Conaghan, Catherine. 2012. "Prosecuting Presidents. The Politics within Ecuador's Corruption Cases". Journal of Latin American Studies 44 (4): 649-678.

De la Torre, Carlos. 2013. "El tecnopopulismo de Rafael Correa. ¿Es compatible el carisma con la tecnocracia?". Latin American Research Review 48(1): 24-43.

Eichorst, Jason y Polga-Hecimovich, John. 2014. "The 2013 Ecuadorian General Elections". Electoral Studies 34: 361-365. http:/ /dx.doi.org/10.1016/j.electstud.2013.09.014

Fenno, Richard Jr. 1973. Home Style: House Members in Their Districts. Boston: Little Brown.

Freidenberg, Flavia. 2012. “Ecuador 2011: Revolución Ciudadana, estabilidad presidencial y personalismo político". Revista de Ciencia Política 32 (1): 129-150.

Fundamedios. 2013. "El silencio asfixiante: la libertad de expression en el Ecuador 2013". Disponible en: http://www.fundamedios.org.ec/sites/default/files/archivos/informe-fundamedios_4.pdf

Gallagher, K., Irwing, A., \& Koleski, K. 2013. “¿Un mejor trato? Análisis comparativo de los préstamos chinos en América Latina". Cuadernos de trabajo. Centro de Estudios China-México Nº 1, 1-40. México: Universidad Nacional Autónoma de México.

Informe Psicosocial y de Derechos Humanos, Caso 10 detenidos en Luluncoto, Operativo Sol Rojo. 2012. "Comisión Ecuménica de Derechos Humanos CEDHU, Proyecto de Reparación Socioambiental Clínica Ambiental y Fundación Regional de Asesoría en Derechos Humanos, INREDH". Disponible en: http://www.inredh.org/archivos/pdf/informe_luluncoto.pdf

Instituto Nacional de Estadísticas y Censos. 2013. “Encuesta Nacional de Empleo, Desempleo y Subempleo, (ENEMDU)". http:/ $/$ www.inec.gob.ec/estadisticas/?option=com_content\&view=article\&id=92\&Itemid=57

Levitsky, Steve y Lucan Way. 2002. "Elections without Democracy. The Rise of Competitive Authoritarianism". Journal of Democracy 13 (2): 51-65.

Levistky, Steve y Kennet Roberts. 2011. “Introduction: Latin America's 'Left Turn': A Framework for Analysis". En The Resurgence of the Latin American Left, Steven Levitsky y Kennet Roberts (eds.). Maryland: The John Hopkins University Press.

Mayhew, David R. 1974. Congress: The Electoral Connection. New Haven: Yale University Press.

Mejía Acosta, Andrés. 2009. Informal Coalitions and Policymaking in Latin America. New York: Routledge.

Méndez, Fernando, Jonathan Weathley y Santiago Basabe-Serrano. 2013. Ecuador Vota. Disponible en: www.ecuadorvota.com

Miller, Gary J. 2005. "The Political Evolution of Principal-Agent Models". Annual Review of Political Science 8: 203-225.

Ministerio de Transporte y Obras Públicas (2013, septiembre 30). Estado de la red vial estatal. [Recuperado el 15 de febrero de 2014 de http:/ / www.obraspublicas.gob.ec/wp-content/uploads/ downloads/2013/10/10-10-2013-Estado-de-la-Red-Vial_MTOP.pdf] 
Polga-Hecimovich, John. 2013. "Overcoming the Regional Cleavage?: The (Unprecedent) Regional Nationalization of Alianza PAIS". Working Paper N ${ }^{0} 1$. Quito: FLACSO Ecuador, Departamento de Estudios Políticos.

Programa de las Naciones Unidas para el Desarrollo. 2013. Informe Regional de Desarrollo Humano 2013-2014. Nueva York: Estados Unidos. Disponible en: http://www.latinamerica.undp.org/content/ $\mathrm{dam} / \mathrm{rblac} / \mathrm{img} / \mathrm{IDH} / \mathrm{IDH}-\mathrm{AL} \% 20$ Informe\%20completo.pdf

\section{Normas legales}

Constitución de la República del Ecuador.

Código Orgánico Integral Penal.

Ley Orgánica Electoral y de Organizaciones Políticas. Código de la Democracia.

\section{Noticias en medios de comunicación}

Agencia de Noticias Andes. "Ecuador prevé una inversión pública de 7.200 millones de dólares para 2014" (16 de enero). [Recuperado el 15 de febrero de 2014 de http:/ / www.andes.info.ec/es/noticias/ ecuador-preve-inversion-publica-7200-millones-dolares-2014.html]

Agencia de Noticias Andes. 2013. "Manual para activistas comunitarios amplifica la guerra de desestabilización al gobierno del Ecuador" (13 de diciembre). [Recuperado el 15 de febrero de 2014 de http:/ / www. andes.info.ec/es/noticias/manual-activistas-comunitarios-amplifica-guerra-desestabilizaciongobierno-ecuador.html]

Agencia de Noticias Andes. 2014. "Política opositora de Ecuador tramita ayuda financiera con la NED de EE.UU. para montar fundación y agencia de noticias, confirma diario público" (7 de enero). [Recuperado el 15 de febrero de 2014 de http://www.andes.info.ec/es/noticias/ politica-opositora-ecuador-tramita-ayuda-financiera-ned-eeuu-montar-fundacion-agencia]

Argenpress.info. 2013. "Ecuador: Tribunal ético por la justicia analizó la criminalización de la protesta" (6 de septiembre). [Recuperado el 15 de febrero de 2014 de http:/ / www.argenpress.info/2013/09/ ecuador-tribunal-etico-por-la-justicia.html]

Diario El Comercio. 2011. "Un CNE afín al Régimen se posesionó" (30 de octubre). [Recuperado el 9 de febrero de $2014 \mathrm{http}$ // / elcomercio.com/politica/CNE-afin-Regimen-posesiono_0_599940220.html]

Diario El Comercio. 2013. “Ecuador renuncia a Atpdea con EE.UU” (27 junio). [Recuperado el 15 de febrero de 2014 de http://elcomercio.com/politica/Snowden-asilo-Ecuador-espionaje-NSA_0_945505536.html]

Diario El Comercio. 2013. "Inquietud por el Código Penal se extiende" (22 de octubre). [Recuperado el 15 de febrero de 2014 de http://www.elcomercio.com/politica/CodigoPenal-medicos-protestamalapractica-Ecuador_0_1015698502.html]

Diario El Comercio. 2014. "El CNE no da repuestas a las quejas de 'campaña sucia'" (22 de enero). [Recuperado el 10 de febrero de 2014 de http://www.elcomercio.com/politica/CNE-repuestasquejas-campana-sucia_0_851914862.html].

Diario El Comercio. 2014. "Médicos y gobierno llegaron a un acuerdo en el Código Penal. (30 de enero). [Recuperado el 10 de febrero de 2014 de http://www.elcomercio.com/salud/Ecuador-medicosCodigo_Penal-coip-mala_practica_medica-salud_0_1075692619.html]

Diario El Comercio. 2014. "Santiago Roldós responde al Presidente" (15 de enero). [Recuperado el 15 de febrero de 2014 de http:/ / www.elcomercio.com/politica/SantiagoRoldos-RafaelCorrea-MilHojasdenuncia_0_1066693392.html]

Diario El Mercurio. 2013. "Al SRI no le gusta fallo judicial a favor del OCP" (20 de septiembre) disponible en: http:/ / www.elmercurio.com.ec/398285-al-sri-no-le-gusta-fallo-judicial-a-favor-del-ocp/\#. UxOqyP15NTI

Diario El Mercurio. 2013. "Condenan a alumnos del Central Técnico" (30 de julio). [Recuperado el 15 de febrero de 2014 de http:/ / www.elmercurio.com.ec/391083-condenan-a-alumnos-del-centraltecnico/\#.Uw4hBeN5MZx] 
Diario El Mercurio. 2013. "Esta semana se entrega dirigente Carlos Pérez Guartambel" (22 de enero). [Recuperado el 15 de febrero de 2014 de http://www.elmercurio.com.ec/366048-esta-semana-seentrega-dirigente-carlos-perez-guartambel/\#.Uw4g-eN5MZx]

Diario El Telégrafo. 2013. "Asambleístas serían suspendidas" (29 de octubre). [Recuperado el 15 de febrero de 2014 de http:/ / www.telegrafo.com.ec/politica/item/asambleistas-serian-suspendidas.html]

Diario El Telégrafo. 2013. "Ecuador va rumbo a un tratado comercial con la Unión Europea" (13 de noviembre). [Recuperado el 15 de febrero de 2014 de http://www.telegrafo.com.ec/economia/ item/ecuador-va-rumbo-a-un-tratado-comercial-con-la-union-europea.html]

Diario El Telégrafo. 2013. "La demanda internacional de Chevron es "prematura"" (22 de noviembre). [Recuperado el 15 de febrero de 2014 de http:/ / www.telegrafo.com.ec/politica/item/la-demandainternacional-de-chevron-es-prematura.html]

Diario El Telégrafo. 2013. "Se afectará menos del 1 por mil del Yasuní" (16 de agosto). [Recuperado el 15 de febrero de 2014 de http:/ /www.telegrafo.com.ec/economia/item/se-afectara-menos-del-1por-mil-del-yasuni.html]

Diario El Telégrafo. 2014. "Corte Constitucional exige emitir otro fallo en litigio entre SRI y OCP" (1 de enero). Disponible en: http://www.telegrafo.com.ec/economia/item/corte-constitucional-exigeemitir-otro-fallo-en-litigio-entre-sri-y-ocp.html

Diario El Telégrafo. 2014. "Omar Simon es el nuevo secretario de Presidencia” (11 de, marzo) [Recuperado el 11 de marzo 2014 http:/ / www.telegrafo.com.ec/politica/item/omar-simon-es-el-nuevo-secretariode-presidencia.html]

Diario El Universo. 2013. "Corte sentencia a 18 meses de prisión al asambleísta Cléver Jiménez" (17 de abril). [http://www.eluniverso.com/2013/04/17/1/1355/abogado-correa-confirma-sentenciaasambleista-clever-jimenez.html]

Diario Hoy. 2013. "Bono de Desarrollo Humano está financiado" (18 de enero). [Recuperado el 15 de febrero de 2014 de http://www.hoy.com.ec/noticias-ecuador/bono-de-desarrollo-humano-estafinanciado-571846.html]

Diario Hoy. 2013. "El Consep fijó la dosis personal de cuatro drogas" (20 de junio). [Recuperado el 15 de febrero de 2014 de http:// www.hoy.com.ec/noticias-ecuador/el-consep-fijo-la-dosis-personal-decuatro-drogas-584045.html]

Diario Hoy. 2014. "En Ambato, los médicos se suman a las protestas" (24 de enero). [Recuperado el 10 de febrero de 2014 de http://www.hoy.com.ec/noticias-ecuador/en-ambato-los-medicos-se-sumana-las-renuncias-599551.html]

Diario Hoy. 2014. "La universidad pública". [Recuperado el 15 de febrero de 2014 de http:/ /www.hoy. com.ec/noticias-ecuador/la-universidad-publica-579857.html]

Diario Hoy. 2014. “Los pedidos de las mujeres a medias en el Código Penal” (8 de octubre). [Recuperado el 10 de febrero de 2014 de http:/ / www.hoy.com.ec/noticias-ecuador/los-pedidos-de-las-mujeresa-medias-en-el-codigo-penal-592408.html]

Diario Hoy. 2014. "La apelación es el recurso legal de los movimientos descalificados" (13 de octubre). [Recuperado el 9 de febrero de 2014 de http:/ / www.hoy.com.ec/noticias-ecuador/la-apelacion-esel-recurso-legal-de-los-movimientos-descalificados-563879.html].

Diario La Republica.ec. 2013. "Niegan apelación de Mery Zamora, condenada a ocho años por el 30S" (14 de noviembre). [http://www.larepublica.ec/blog/politica/2013/11/14/ niegan-apelacion-de-mery-zamora-condenada-a-ocho-anos-por-el-30s/]

Diario La República. 2014. "Presidencia presentará queja por caricatura de Bonil" (4 de enero). [Recuperado el 15 de febrero de 2014 de https:/ /www.larepublica.ec/blog/politica/2014/01/04/ presidencia-presentara-queja-caricatura-bonil/]

Ecuavisa. "Jaime Guevara narra su incidente con Rafael Correa" (12 de septiembre). [Recuperado el 15 de febrero de 2014 de http://www.ecuavisa.com/articulo/lo-mejor-del-2013/ septiembre/39855-jaime-guevara-narra-su-incidente-rafael-correa]

The Washington Post. 2013. “Edward Snowden flees Hong Kong for Moscow, asks Ecuador to grant him asylum" (23 de junio). [Recuperado el 15 de febrero de 2013 de http:/ / www.washingtonpost.com/ world/snowden-departs-hong-kong-for-a-third-country-government-says/2013/06/23/08e9eff2dbde-11e2-a9f2-42ee3912ae0e_story.html] 
Santiago Basabe-Serrano es becario Georg Foster de la Fundación Alexander von Humboldt e Investigador postdoctoral del Instituto Alemán de Estudios Globales y de Área (GIGA), en Hamburgo-Alemania. Además es profesor titular del Departamento de Estudios Políticos de la Facultad Latinoamericana de Ciencias Sociales, FLACSO Ecuador (en licencia). Sus áreas de investigación se concentran en las relaciones entre política y justicia, presidencialismo y estudios legislativos. Algunas de sus investigaciones recientes han sido publicadas en revistas académicas como Justice System Journal, International Journal of Law, Crime and Justice, Perfiles Latinoamericanos, Political Research Quarterly y Journal of Latin American Studies.

Página web personal: www.santiagobasabe.com

E-mail: Santiago.Basabe@giga-hamburg.de

Julián Martínez Ramos es psicólogo de la Universidad Nacional de Córdoba (Argentina). Actualmente es candidato a Maestro en Ciencia Política en la Facultad Latinoamericana de Ciencias Sociales, FLACSO Ecuador. Sus áreas de interés investigativo son el comportamiento político individual, los estudios legislativos y los estudios electorales.

E-mail: julian.martinez.r@gmail.com 